\title{
Expansion of TAVR into Low-Risk Patients and Who to Consider for SAVR
}

\author{
Kunal V. Patel • Wally Omar • Pedro Engel Gonzalez • \\ Michael E. Jessen - Lynn Huffman • Dharam J. Kumbhani • \\ Anthony A. Bavry (D)
}

Received: June 23, 2020 / Published online: September 1, 2020

(C) The Author(s) 2020

\section{ABSTRACT}

Transcatheter aortic valve replacement (TAVR) has revolutionized the treatment of severe aortic stenosis (AS) over the last decade. The results of the Placement of Aortic Transcatheter Valves (PARTNER) 3 and Evolut Low Risk trials demonstrated the safety and efficacy of TAVR in low-surgical-risk patients and led to the approval of TAVR for use across the risk spectrum. Heart teams around the world will now be faced with evaluating a deluge of younger, healthier patients with severe AS. Prior to the PARTNER 3 and Evolut Low Risk studies, this heterogenous patient population would have undergone surgical aortic valve replacement (SAVR). It is unlikely that TAVR will completely supplant SAVR for the treatment of severe AS in patients with a low surgical risk, as SAVR has excellent short- and long-term outcomes and years of durability data. In this review, we

Digital Features To view digital features for this article go to https://doi.org/10.6084/m9.figshare. 12770000 .

K. V. Patel · W. Omar · P. E. Gonzalez .

D. J. Kumbhani · A. A. Bavry (ه)

Division of Cardiology, University of Texas

Southwestern Medical Center, Texas, USA

e-mail: anthony.bavry@utsouthwestern.edu

M. E. Jessen · L. Huffman

Department of Cardiovascular and Thoracic Surgery,

University of Texas Southwestern Medical Center,

Texas, USA outline the critical role that SAVR will continue to play in the treatment of severe AS in the postPARTNER 3/Evolut Low Risk era.

Keywords: Aortic stenosis; Low risk; SAVR; TAVR

\section{Key Summary Points}

The PARTNER 3 and Evolut Low Risk trials will greatly expand the use of TAVR to a significantly larger group of eligible patients with severe aortic stenosis.

SAVR remains a vital treatment choice in patients with high anatomical risk including bicuspid aortic valve, heavy annular calcification, and low coronary heights.

The long-term impact of increased pacemaker use, paravalvular regurgitation, and durability concerns associated with transcatheter heart valves is still unknown.

Leaflet thickening and future coronary reaccess remain significant concerns with TAVR. 


\section{INTRODUCTION}

In the last decade, the development of transcatheter aortic valve replacement (TAVR) has dramatically changed the management of symptomatic severe aortic stenosis (AS). Early studies showed a clear benefit with TAVR in prohibitive and high-surgical-risk patients (Society of Thoracic Surgery-Predicted Risk of Mortality [STS-PROM] $>8 \%$ ) $[1,2]$. With ongoing refinement of TAVR technology, more accurate methods of annular sizing, and improvements in procedural technique, TAVR use has expanded to AS patients at intermediate surgical risk (STS-PROM 4-8\%) [3, 4]. An analysis of surgical aortic valve replacements (SAVR) between 2002 and 2010 found that $80 \%$ of SAVRs are being performed in patients with low surgical risk (STS-PROM $<4 \%$ ) [5]. While, the population of patients with AS who qualify as low-risk after integrating other markers of risk with the STS-PROM may actually be lower ( $\sim 50 \%)$, this still represents a large pool of patients [6]. Low-risk patients undergoing SAVR are, on average, 65 years old, lack significant medical comorbidities, receive a bioprosthetic valve at a rate of $75 \%$, and have short-term mortality of $1.7 \%$ [5]. The publication of the Placement of Aortic Transcatheter Valves (PARTNER) 3 and Evolut Low Risk trials in 2019 has created excitement around expanding TAVR into the large pool of low-risk patients $[7,8]$. While the number of low-risk AS patients treated with TAVR is bound to increase, a close analysis of the low-risk trials indicates that SAVR will continue to play a major role in many AS patients. In this review, we aim to identify low-surgical-risk patients with severe AS who may be considered for SAVR in the post-PARTNER 3/Evolut Low Risk trial era. This article is based on previously conducted studies and does not contain any studies with human participants or animals performed by any of the authors.

\section{SUMMARY OF LOW-RISK TRIALS}

The classification of a patient as having low surgical risk goes beyond their STS-PROM score.
According to the valvular heart disease guidelines, a low-surgical-risk patient is one who has an STS-PROM $<4 \%$, lacks any of the major indices of frailty, lacks any major organ system compromise, and has no procedural impediments (Fig. 1) [9]. Having any one of these factors pushes a patient up into the intermediate risk group despite having a low STS-PROM. The heart team plays a vital role in integrating the STS-PROM with additional risk factors to determine the patient's overall operative risk. To be eligible for the low-risk TAVR trials, patients had to meet strict inclusion and exclusion criteria (Fig. 2) [7, 8]. After the initial screen, an independent screening committee reviewed each patient's clinical and radiographic data to determine eligibility for randomization. Patients with known bicuspid valves, heavy left ventricular outflow tract (LVOT) calcification, small effaced sinuses of Valsalva, a narrow or heavily calcified sinotubular junction (STJ), or those at high risk of prosthesis patient mismatch were excluded in both trials.

After this rigorous enrollment process, over 2300 patients were randomized to either TAVR or SAVR between the two trials (Fig. 3) [7, 8]. The baseline clinical characteristics were remarkably similar between the two trials with an average age of 73 years, 30\% women, an STSPROM of $1.9 \%$, and a lack of significant comorbidities. In the PARTNER 3 trial, over 95\% of patients undergoing TAVR had $\mathrm{a} \geq 23-\mathrm{mm}$ Sapien S3 valve while in the Evolut Low Risk trial over $95 \%$ of patients had a $\geq 26-\mathrm{mm}$ valve (74\% Evolut R, 22\% EvolutPro, 3.6\% CoreValve). In both trials, nearly $80 \%$ of patients undergoing SAVR had $\geq 23-\mathrm{mm}$ prosthetic valve implanted. Of note, this is in contrast to the STS SAVR registry where only around 60\% of patients receive a valve $\geq 23 \mathrm{~mm}$ in size [5].

The primary outcome in PARTNER 3 of death, stroke, or rehospitalization was reached in $8.5 \%$ of TAVR patients versus $15.1 \%$ of SAVR patients at 1 year, which met statistical significance for superiority. In the Evolut Low Risk trial, the primary endpoint of death or disabling stroke was reached in 5.3\% of TAVR patients versus $6.7 \%$ of SAVR patients at 2 years, which met statistical significance for non-inferiority. The need for a permanent pacemaker (PPM) was 
Integrative Criteria For Low-Surgical Risk Determination

(must meet all 4 criteria)

\begin{tabular}{|c|c|c|}
\hline \multicolumn{3}{|l|}{ STS-PROM $<4 \%$} \\
\hline Lack of frailty & Impairment in Katz activities of daily living & $\begin{array}{l}\text { Feeding, bathing, dressing, transferring, toileting, urinary } \\
\text { incontinence }\end{array}$ \\
\hline \multirow{7}{*}{$\begin{array}{l}\text { No major organ } \\
\text { system compromise }\end{array}$} & Impairment in ambulation & No walking aid or assist; 5-meter walk $<6 \mathrm{sec}$ \\
\hline & Cardiac dysfunction & $\begin{array}{l}\text { Severe LV systolic or diastolic dysfunction, severe RV } \\
\text { dysfunction, fixed pulmonary hypertension }\end{array}$ \\
\hline & Renal dysfunction & CKD stage 3 or greater \\
\hline & Pulmonary dysfunction & FEV $1<50 \%$ or DLCO $<50 \%$ of predicted \\
\hline & Central nervous system abnormality & Dementia or stroke with persistent limitation \\
\hline & Gastrointestinal and nutritional deficiency & Inflammatory bowel disease or serum albumin $<3.0 \mathrm{~g} / \mathrm{dL}$ \\
\hline & $\begin{array}{l}\text { Active malignancy } \\
\text { Cirrhosis }\end{array}$ & \\
\hline$\frac{\text { No procedure specific }}{\text { impediments }}$ & $\begin{array}{l}\text { Porcelain aorta, chest wall malformatior } \\
\text { wall, history of radiation to the chest }\end{array}$ & onary artery bypass \\
\hline
\end{tabular}

Fig. 1 Integrative criteria for low-surgical-risk determination. Society of Thoracic Surgery-predicted risk of mortality (STS-PROM); left ventricle (LV); right ventricle
(RV); chronic kidney disease (CKD); forced expiratory volume in $1 \mathrm{~s}$ (FEV1); diffusing capacity of lung for carbon monoxide (DLCO). Adapted from Nishimura et al. [9]

Inclusion Criteria $\quad \begin{aligned} & \text { STS-PROM } \\ & \text { Heart team approach to deem integrated } \\ & \text { low surgical risk }\end{aligned}$
Transfemoral or transaxillary access
Exclusion Criteria
Bicuspid aortic valve
Complex coronary artery disease
Recent MACE
Expected life expectancy < 24 months
Severe comorbid valvular disease
amenable to surgical repair
Significant aortopathy
Hypertrophic obstructive cardiomyopathy
Prohibitive LVOT calcification
Sinus of Valsalva unsuitable

$\begin{array}{cc}\begin{array}{c}\text { PARTNER 3 } \\ <4 \%\end{array} & \begin{array}{c}\text { Evolut Low Risk } \\ <3 \%\end{array} \\ \text { Yes } & \text { Yes } \\ \text { Transfermoral only } & \begin{array}{c}\text { Both allowed } \\ (99 \% \text { TF })\end{array} \\ \text { Yes } & \text { Yes } \\ \text { YNTAX, UPLMD } & \text { SYNTAX }>32, \text { UPLMD } \\ \text { Yes } & \text { Yes } \\ \text { Yes } & \text { Yes } \\ \text { Yes } & \text { Yes } \\ \text { Yes } & \text { Yes } \\ \text { Yes } & \text { Yes } \\ \text { Yes } & \text { Yes } \\ \text { Yes } & \text { Yes }\end{array}$

Fig. 2 Inclusion and exclusion criteria for the low-risk trials. Society of Thoracic Surgery-predicted risk of mortality (STS-PROM); synergy between percutaneous

7.3\% for TAVR and 5.4\% for SAVR in PARTNER 3 and $19.4 \%$ for TAVR and $6.7 \%$ for SAVR in the Evolut Low Risk trial. The rate of severe prosthesis patient mismatch was $4.3 \%$ for TAVR and $6.3 \%$ for SAVR in PARTNER 3 and $1.8 \%$ for TAVR and $8.2 \%$ for SAVR in Evolut Low Risk. The mean gradient at 1 year was $13.7 \mathrm{mmHg}$ for TAVR and $11.3 \mathrm{mmHg}$ for SAVR in PARTNER 3 and $8.6 \mathrm{mmHg}$ for TAVR and $11.2 \mathrm{mmHg}$ for coronary intervention with Taxus and cardiac surgery (SYNTAX); transfemoral (TF); unprotected left main disease (UPLMD); left ventricular outflow tract (LVOT)

SAVR in Evolut Low Risk. The rate of moderate or greater paravalvular leak (PVL) was $0.6 \%$ for TAVR and $0.5 \%$ for SAVR in PARTNER 3 and $3.6 \%$ for TAVR and $0.6 \%$ for SAVR in Evolut Low Risk. Overall, these results demonstrated the safety of TAVR in a carefully selected lowsurgical-risk population at 1-2 years of followup. However, the impact of certain high-risk anatomical features, post-TAVR complications 


\begin{tabular}{|c|c|c|c|}
\hline & \multicolumn{2}{|c|}{ PARTNER 3} & \\
\hline & TAVR & SAVR & \\
\hline Age (years) & 73.3 & 73.6 & \\
\hline$\%$ Female & $32.5 \%$ & $28.9 \%$ & \\
\hline STS-PROM \% & 1.9 & 1.9 & \\
\hline Concomitant $\mathrm{PCI} / \mathrm{CABG}$ & $6.5 \%$ & $12.8 \%$ & \\
\hline \multirow{2}{*}{ Primary outcome } & \multicolumn{3}{|c|}{ Death, stroke, rehospitalization at 1 year $^{1}$} \\
\hline & $8.5 \%$ & $15.1 \%$ & $p<0.05$ \\
\hline Death 1 year & $1 \%$ & $2.5 \%$ & NS \\
\hline Stroke 1 year & $1.2 \%$ & $3.1 \%$ & NS \\
\hline Rehospitalization & $7.3 \%$ & $11 \%$ & $p<0.05$ \\
\hline New pacemaker & $7.3 \%$ & $5.4 \%$ & NS \\
\hline Mean Gradient ( 1 year) & $13.7 \mathrm{mmHg}$ & $11.3 \mathrm{mmHg}$ & \\
\hline$\geq$ Moderate PVL at 1 year & $0.6 \%$ & $0.5 \%$ & \\
\hline New LBBB & $23.7 \%$ & $8 \%$ & \\
\hline
\end{tabular}

\begin{tabular}{ccl}
\multicolumn{3}{c}{ Evolut Low Risk } \\
TAVR & SAVR & \\
74 & 73.8 & \\
$36.2 \%$ & $33.5 \%$ & \\
1.9 & 1.9 & \\
$6.9 \%$ & $13.6 \%$ & \\
Death or disabling stroke at 2 years & \\
$5.3 \%$ & $6.7 \%$ & $\mathrm{p}<0.05$ \\
$2.4 \%$ & $2.9 \%$ & $\mathrm{NS}$ \\
$0.8 \%$ & $2.1 \%$ & $\mathrm{p}<0.05$ \\
$3.6 \%$ & $6.7 \%$ & $\mathrm{p}<0.05$ \\
$19.4 \%$ & $6.7 \%$ & $\mathrm{p}<0.05$ \\
$8.6 \mathrm{mmHg}$ & $11.2 \mathrm{mmHg}$ & \\
$3.6 \%$ & $0.6 \%$ & \\
$\mathrm{NR}$ & $\mathrm{NR}$ &
\end{tabular}

Fig. 3 Low-risk trial outcomes. ${ }^{1}$ Met statistical significance for non-inferiority and superiority; ${ }^{2}$ Met statistical significance for non-inferiority. Transcatheter aortic valve replacement (TAVR); surgical aortic valve replacement (SAVR); Society of Thoracic Surgery-predicted risk of

mortality (STS-PROM); percutaneous coronary intervention (PCI); coronary artery bypass graft surgery (CABG); paravalvular leak (PVL); left bundle branch block (LBBB); not significant (NS); not reported (NR)

including PPM implantation and PVL, as well as unknown long-term durability of TAVR outline areas where SAVR should be strongly considered in treating severe low-risk AS patients.

\section{ANATOMIC FACTORS FAVORING SAVR}

\section{Bicuspid Aortic Valve}

Approximately $2 \%$ of the general population have a bicuspid aortic valve, and among all AS patients undergoing SAVR up to $49 \%$ have been found to have bicuspid anatomy [10]. When stratified by age, those over 70 years had a $38 \%$ rate of bicuspid AS compared to a $62 \%$ among those ages of 50-70 years [10]. Although these data were from a study of surgical patients, it suggests that as we expand TAVR into low-risk patients, a larger proportion will be found to have bicuspid anatomy. Bicuspid valves often have heavy asymmetric calcification, associated aortopathy, and present unique anatomical challenges for TAVR due to the often non-circular implantation of the transcatheter heart valve (THV) [11-13]. These challenges may increase the risk of periprocedural

complications including annular rupture, asymmetric valve deployment, and paravalvular leak (PVL), which may all impact short- and long-term outcomes with TAVR [14].

Studies of early generation THVs in bicuspid AS found that, compared to trileaflet AS patients treated with TAVR, bicuspid patients experienced higher rates of open conversion, significant PVL, and PPM implantation $[15,16]$. With the use of CT-guided annular sizing, advances in the sealing mechanism of newer THVs, and operator experience, outcomes of TAVR for bicuspid AS have improved [16-19]. However, conversion to open surgery, peri-procedural stroke, and need for PPM continue to remain significantly higher in bicuspid patients with newer-generation THVs [18]. Computed tomography (CT) studies of implanted THVs in patients with bicuspid AS have found suboptimal, non-circular valve expansion in bicuspid patients, which may impact long-term valve performance and the rate of valve degeneration [14].

Studies directly comparing SAVR to TAVR in bicuspid AS are scant; however, one study from the National Inpatient Sample of nearly 2000 propensity-matched patients found no major difference in in-hospital mortality or stroke 
between TAVR and SAVR [20]. Interestingly, SAVR was associated with significantly lower mortality among patients under 65 years of age and significantly lower rates of PPM implantation [20]. A smaller study prospectively studying low-risk patients with bicuspid AS demonstrated low rates of in-hospital mortality and stroke with TAVR; however, longer-term follow-up with a larger patient population is needed [21]. For low-risk bicuspid AS patients with associated aortopathy (ascending aortic dimension $>4.5 \mathrm{~cm}$ ), SAVR with aortic root repair should be the preferred treatment $[22,23]$. Given the unique challenges of bicuspid anatomy, SAVR will continue to have a central role in the management of low-risk severe bicuspid AS patients until more data is available on short- and long-term outcomes [24].

\section{Pure Native Aortic Valve Regurgitation}

Despite advances in THVs in patients with AS, the use of TAVR for aortic regurgitation has been limited and remains off-label in the United States. Unlike AS, the etiology of aortic regurgitation may originate at the leaflet or aortic root level [25]. Several anatomical considerations make SAVR a more suitable therapy for low-surgical-risk patients with aortic regurgitation including the lack of sufficient calcium for THV anchoring, often dilated aortic root, and risk of PVL [26]. Many patients with pure aortic regurgitation have a bicuspid aortic valve which may further increase the complexity and result in a suboptimal transcatheter result [16]. Registry data show that even with newer-generation THVs, there remained a $3.8 \%$ risk of open conversion, a $12.7 \%$ risk of needing a second $\mathrm{THV}$, an $18.6 \% \mathrm{PPM}$ rate, and a $4.2 \%$ risk of moderate or greater residual aortic regurgitation [26]. Trials with specialized THVs designed for aortic regurgitation are ongoing (NCT02732704). Until more data are available, SAVR remains the treatment of choice for pure aortic regurgitation for low-surgical-risk patients.

\section{Small Aortic Annulus}

The prevalence of patients with AS and a small aortic annulus is as high as $17 \%$ and predominantly affects older women [27]. Although there are no universally accepted criteria for what qualifies as a small aortic annulus, many propose an annular diameter of $<21-23 \mathrm{~mm}$ [28-30]. Small aortic annulus has several shortand long-term implications for patients with severe symptomatic AS principally prosthesis patient mismatch and the sequela of this condition [31-33]. Prosthesis patient mismatch occurs at an indexed effective orifice area of less than $0.85 \mathrm{~cm}^{2} / \mathrm{m}^{2}$, and those patients with an EOAi less than $0.65 \mathrm{~cm}^{2} / \mathrm{m}^{2}$ are classified as severe [34]. Severe prosthesis patient mismatch has been consistently shown to predict worse long-term outcomes including mortality [34-36]. The rate of severe prosthesis patient mismatch is higher in SAVR than for TAVR likely because of the ability to oversize a THV for a patient's annular size [37-39]. However, patients with small aortic annulus receiving TAVR still have a $4-20 \%$ rate of severe prosthesis patient mismatch [37-39]. Additionally, oversizing THVs in small aortic annulus patients with heavy asymmetric annular and LVOT calcification can increase the risk of annular rupture and coronary obstruction [40, 41].

SAVR in low-risk patients allows for the possibility of aortic root enlargement, which is effective at reducing the rate of post-operative prosthesis patient mismatch by up to $50 \%$ and results in lower 30 days and long-term morbidity and mortality [28, 29, 42]. Importantly, in younger low-risk patients, root enlargement with SAVR as a first operation would allow for a larger THV during valve-in-valve TAVR when the first bioprosthesis fails [31]. In those small aortic annulus patients who are younger and at a low bleeding risk, SAVR with a mechanical prosthesis can also be considered to obviate the need for a second valve procedure and further limit the risk of PPM. Although randomized studies are ongoing to compare TAVR versus SAVR in small aortic annulus patients (VIVA Trial NCT 03383445), SAVR will likely play a role in low-surgical-risk patients with severe AS and a small aortic annulus. 
Heavy Annular and LVOT Calcification, Stroke, and PVL

In both the PARTNER 3 and Evolut Low Risk trials, the final decision to randomize patients rested with a case review committee analyzing all clinical and imaging data. Of the patients who failed review in PARTNER 3, 38\% failed due to severe LVOT calcium and $17 \%$ failed due to hostile aortic root while $8 \%$ failed due to severe LVOT calcium in the Evolut Low Risk trial [7, 8]. Although there is no objective or universally accepted criteria for determining the severity of annular and LVOT calcification, the presence of either has been associated with worse outcomes with TAVR including annular rupture, stroke, and paravalvular leak [43, 44]. LVOT calcium, especially in oversized balloon-expanded valves (BEV) and self-expanding valves (SEV) requiring post-dilation, increase the risk of annular rupture, which is associated with over 50\% mortality [40, 44, 45]. Heavy annular/LVOT calcification is also linked to increased rates of $\geq$ moderate PVL, which is associated with worse outcomes and was more frequently seen in the early TAVR trials [44, 46-49]. The incidence of $\geq$ moderate PVL was $0.6-3.6 \%$ in the low-risk trials, likely due in part to excluding heavily annular/LVOT calcification, improvements in THV technology, and the frequent use of post-dilation $(20-30 \%)$ [7, 8]. The rate of $\geq$ moderate PVL was approximately $15 \%$ in the low-risk subset of the Nordic Aortic Valve Intervention (NOTION) study, which did not systematically exclude patients with heavy annular/LVOT calcification [50]. Additionally, 29-34\% TAVR patients had mild PVL in the low-risk trials at 1 year, and how this affects THV and left ventricular performance over extended follow-up is still unknown $[7,8]$. Among high-surgical risk patients, mild-PVL was associated with increased mortality at 2-year follow-up [51]. An advantage of SAVR is the ability to directly visualize and surgically remove heavy calcification at the time of AVR resulting in $<1 \%$ rates of significant PVL $[7,8]$.

Calcium and atheromatous embolization also play a key role in the underlying mechanism of stroke after TAVR. The manipulation of wires and catheters in the aortic arch, pre-TAVR balloon aortic valvuloplasty (BAV), THV positioning, and post-dilation all serve to liberate calcific deposits. The ability of cerebral embolic protection devices to modify stroke risk with TAVR remains controversial given conflicting data [52, 53]. Initially, stroke was a major drawback of TAVR, however 30-day disabling stroke rates have come down dramatically from $5-6 \%$ to $0.6-2 \%$ in the low-risk trials $[1-4,7,8]$. Post-dilation has been shown to confer a 2.5 fold increase in stroke and was performed in $20-30 \%$ of patients in the low-risk trials [7, 8, 54, 55]. Excluding patients with heavy annular/LVOT calcification may partially explain the extremely low rate of stroke in the low-risk trials. As TAVR continues to expand into low-risk patients, SAVR should strongly be considered in patients with heavy, asymmetric calcification patterns given its link to annular rupture, significant PVL, and stroke.

\section{Alternative Access}

The vast majority of TAVRs are performed via transfemoral (TF) access. In the Evolut Low Risk trial, the use of alternative access was approximately $1 \%$, and a lack of TF access was an exclusion criteria for PARTNER 3 [7, 8]. Alternative modes of access include transthoracic access (direct aortic and transapical) and nonfemoral peripheral access (transaxillary, transcarotid, and transcaval). Patients who lack TF access are more likely to be obese men with peripheral arterial disease [56]. All modes of alternative access have been associated with higher mortality and stroke compared to TF patients with markedly worse outcomes for transapical, direct aortic, and transcaval patients [57-63]. Newer technology such as intravascular lithotripsy to accommodate the TAVR delivery sheaths in patients with stenotic calcified iliofemoral vessels is actively being studied and holds promise [64]. However, given the morbidity and mortality associated with alternative access TAVR, and the exclusion of these patients from the low-risk trials, SAVR should remain the preferred choice in low-surgical-risk patients without TF access. 


\section{Low Coronary Heights at Risk for Obstruction}

The rate of coronary obstruction is rare, occurring in less than $1 \%$ of TAVR cases but is associated with high procedural morbidity and mortality [41]. Coronary obstruction typically occurs due to displacement of the native valve leaflets and any associated calcium. Identification of patients at risk of coronary obstruction has markedly improved, and patients with coronary ostia less $10-11 \mathrm{~mm}$ above the nadir of the associated sinus, effaced sinuses, and a narrow STJ are at higher risk of occlusion [41]. This often affects the left coronary ostium and is seen more frequently in women, patients with a small aortic annulus and effaced sinuses, bicuspid aortic valves, and during valve-in-valve TAVR [41]. Over $90 \%$ of these cases can be rescued with percutaneous coronary intervention, however one study found an $8.3 \%$ mortality rate [41]. The use of a chimney-stent to protect a coronary artery at risk of post-TAVR obstruction has shown good mid-term survival rates, however long-term data and coronary re-access issues remain in these patients [65]. Studies of the bioprosthetic or native aortic scallop intentional laceration to prevent iatrogenic coronary artery obstruction (BASILICA) technique has been shown to prevent coronary obstruction [66]. However, these studies were primarily done in intermediate and high-surgical-risk patients. Therefore, SAVR should remain the mode of treatment for low-surgicalrisk patients with severe AS at significant risk of TAVR-induced coronary obstruction.

\section{POST-TAVR COMPLICATION RISKS: PACEMAKER AND LEFT BUNDLE BRANCH BLOCK (LBBB)}

Conduction disturbances and the need for a PPM continues to remain high in patients undergoing TAVR despite improvements in THV technology, operator experience, and expansion to low-surgical-risk patients. The His bundle runs just below the aortic annulus and is subject to mechanical injury from both BEV and
SEVs $[67,68]$. While risk prediction models of atrioventricular (AV) block for specific valve types are in development, a baseline right bundle branch block, 1st degree AV block, THV implantation depth and a short membranous septum have all been found to predict need for PPM implantation [69-73]. Studies of how PPM implantation affects long-term outcomes in TAVR patients have been mixed, but some have shown up to a $40 \%$ increase in 1-year mortality and nearly a doubling in risk of heart failure admission [70, 74-76]. Importantly, there is also marked center-to-center variability in how patients are selected for post-TAVR PPM implantation [77]. In one survey, $15 \%$ of centers reported implanting a PPM prophylactically for a new LBBB after TAVR [77]. There was a 6.5, 17.4, and 34\% risk of 30-day PPM implantation after TAVR in the PARTNER 3, Evolut Low Risk, and NOTION low-risk studies, respectively, and rates in the SAVR group were markedly lower $[7,8]$. Likewise, the development of isolated, persistent LBBB is common after TAVR and was found in $22 \%$ of TAVR patients in the PARTNER 3 trial $[7,8]$. The long-term implications of a new LBBB after TAVR are mixed $[69,78]$. While the risk of $\mathrm{AV}$ block alone should not dictate how we treat low-risk AS, the potential downsides of TAVR, including the need for a PPM and new LBBB, should be discussed with patients. These complications from TAVR may subject patients to future procedures such as generator changes and device upgrades for right ventricular pacing induced cardiomyopathy. Younger low-risk patients who are at a higher risk of AV block may elect to undergo SAVR to avoid these potential future sequela of TAVR.

\section{LONG-TERM CONSIDERATIONS}

With the approval of both the Edwards Sapien 3 and Medtronic Evolut valves for low-surgical risk patients, it is likely that the age at which patients are referred for TAVR will progressively decrease. The mean age of patients in the lowrisk trials was between 73 and 79 years and is approximately 80 years of age in TAVR registries $[7,8,79]$. While most would agree that the findings from the low-risk trials greatly inform 
the 1-year safety of performing TAVR on lowrisk patients over the age of 70 , the best strategy for younger patients and those with a longer life expectancy remains unclear. The durability of both surgical and transcatheter bioprosthetic valves is not indefinite, thus for low-surgicalrisk patients under 50 years of age, without a contraindication to anticoagulation, a mechanical valve is still recommended by most guidelines [80]. At 15-year follow-up, patients under the age of 55 receiving a mechanical aortic valve had a lower mortality than those receiving a surgical bioprosthetic valve [81]. This was in part driven by the mortality associated with re-operation of a failed bioprosthetic valve [81]. In younger low-risk patients, the optimal treatment strategy of AS should incorporate the risk of anticoagulation and bleeding, patient life expectancy, risk of re-intervention for bioprosthetic valve failure, need for coronary re-access, and patient preference [82].

\section{Bioprosthetic Valve Failure}

There are ample data on the long-term durability of bioprosthetic surgical valves, with approximately $23 \%$ primary bioprosthetic valve failure rates at 15 years [83]. Importantly, the age at which bioprosthetic SAVR is performed impacts the rate of bioprosthetic valve failure. Patients under 65 years of age who undergo bioprosthetic SAVR have a $\sim 26 \%$ rate of bioprosthetic valve failure while those 65 years and older have a $\sim 9 \%$ rate of this complication 15 years after valve implantation [83]. The method of defining bioprosthetic valve failure is vital to understanding valve durability. The surgical literature defines bioprosthetic valve failure as patients who actually undergo surgical re-operation [84]. In the era of valve-in-valve (ViV) TAVR, many patients with prohibitive surgical risk who would previously be declined for surgery, and thus not "counted" as bioprosthetic SAVR failure, are now being treated with ViV-TAVR. Data from the ViV International Database (VIVID) show that the average time from bioprosthetic SAVR to ViV-TAVR is 9 years [85]. As more patients undergo ViV TAVR, our understanding of the durability of surgical bioprosthetic valves is likely to evolve. For THVs, long-term durability beyond $5-8$ years is poorly understood and short-term durability appears similar between SEV and BEV [86-88]. Unlike the definition of bioprosthetic valve failure in SAVR studies, there are numerous proposed methods of defining structural valve degeneration (SVD) and bioprosthetic valve failure after TAVR [89]. SVD defined by the European Association of Percutaneous Cardiovascular Interventions (EAPCI) is divided into mild, moderate, and severe based on the mean gradient, change in mean gradient from the initial post-procedural assessment, and degree of intraprosthetic regurgitation [90]. Bioprosthetic valve failure is defined as a THV with severe hemodynamic compromise either requiring intervention or causing death [91]. The Valve Academic Research Consortium (VARC) criteria define severe structural valve dysfunction as a mean gradient $>40 \mathrm{mmHg}$ (moderate to severe stenosis), $\quad$ EOAi $<0.6-0.65 \mathrm{~cm}^{2} / \mathrm{m}^{2} \quad$ (severe patient prosthesis mismatch), DVI $<0.35$, or moderate-to-severe prosthetic valve regurgitation [91]. At 5-8 years THVs have a 3.6-10.8, $0-2.5,0.6-7.5 \%$ for moderate SVD, severe SVD, and bioprosthetic valve failure, respectively [92]. Numerous factors unique to TAVR can affect long-term durability including THV crimping, post-dilation, noncircular implantation, PVL, and leaflet thrombosis [93]. Hypoattenuating leaflet thickening (HALT) and hypo-attenuation affecting motion (HAM), both likely caused by leaflet thrombus formation, have been associated with SVD and postTAVR stroke $[89,94]$. While less commonly seen in SAVR patients, HAM and HALT have been reported in up to $40 \%$ of TAVR $[95,96]$.

A critical implication of bioprostheses durability is how the life-span of the valve compares to the life expectancy of the patient and the possibility of needing a second valve replacement. Indeed, in younger low-risk patients who have a $>15$-year life expectancy, it is reasonable to consider implantation of a mechanical valve given the lower rate of mechanical aortic valve failure compared to surgical bioprosthetic valve failure [81]. For failed bioprosthetic surgical valves, there is a growing body of data 
demonstrating the safety and short-term clinical efficacy of implanting a THV (TAV-in-SAV) $[97,98]$. Among patients in the TAV-in-SAV substudy of PARTNER 2 and CoreValve Pivotal Extreme risk trials, TAV-in-SAV 30-day mortality was approximately $2.6 \%$ with stable THV hemodynamics out to 3 years [99-102]. TAV-inSAV patients in the VIVID registry had a 5.3\% overall mortality at 30 days [103]. When TAVin-SAV outcomes are compared to re-do SAVR, limited available data show comparable 30-day and 3-year mortality [104, 105]. On the contrary, limited data exist on the treatment of a failed THV valve. Surgical removal and replacement of a failed THV can be a complex surgery potentially requiring aortic root replacement while the implantation of a second THV (TAV-in-TAV) has not been widely performed. A recent registry study found that $0.3 \%$ of TAVRs were TAV-in-TAV procedures done predominantly for valvular regurgitation with $2.9 \%$ overall mortality, low rates of stroke and coronary obstruction, but a $9 \%$ rate of $\geq$ moderate PVL [106]. As TAVR patients continue to live longer, our understanding of long-term bioprosthetic valve durability will improve so we can better inform our decision on the best "first implanted valve" in younger, low-risk AS patients.

\section{Coronary Access}

Given the lack of direct visualization of the aortic root during implantation of a THV, the interplay of the implanted valve commissures, aortic root geometry, displaced native aortic valve leaflets, and coronary sinus calcification can limit access to the coronary ostia after TAVR. The rate of coronary artery disease (CAD) in TAVR patients ranges from 40 to $75 \%$ and as TAVR expands to low-risk patients, it is likely that these patients may require future coronary angiography and percutaneous coronary intervention (PCI) for either urgent or elective indications [107]. One study reported a 10\% rate of acute coronary syndrome after TAVR with $47 \%$ of cases occurring within the first year [108]. A MDCT study of TAVR patients found that in $51 \%$ of cases, the ostia of one or both of the coronary arteries was blocked by the neo-commissure of the THV [109]. This is particularly problematic in patients needing a TAV in TAV procedure where there are two THVs with neocommissures that could both block access to the coronary arteries. In patients receiving SAVR, there is direct visualization of the aortic annulus during implantation and re-accessing the coronary arteries is done routinely. As TAVR expands into younger low-risk patients, the ability to re-access the coronary arteries may prove to be a major limitation of TAVR, particularly with the SEV [110].

\section{Quality of Life (QOL)}

A key secondary endpoint studied in both the PARTNER 3 and Evolut Low Risk trials was QOL measured as the change in Kansas City Cardiomyopathy Questionnaire Overall Summary (KCCQ-OS) score. In both trials, there was a marked improvement in the KCCQ-OS score for TAVR patients at 30 days and 1 year $[7,8]$. Importantly, TAVR performed better than SAVR in regard to KCCQ-OS at 30 days, however by 12 months there was minimal difference between the two groups in both trials $[7,8]$. Prior analyses of the PARTNER 1 and CoreValve extreme risk trials, as well as analysis of the STS/ TVT registry, have shown similar improvements in QOL extending out to 3 years [111-113]. These findings are reassuring for low-risk patients who are weighing the recovery from these two treatment modalities as they will likely enjoy the same, marked improvement in QOL by 1 year regardless of the strategy they pursue.

Women have consistently been shown to have differential short- and long-term outcomes after TAVR compared to men. Early studies of the earlier generation THVs in high and intermediate surgical risk patients showed that women had improved survival compared to men at 1 year [114-116]. However, treatment of severe aortic stenosis in women studies of the newer-generation THVs have shown no significant long-term differences in mortality between men and women [117]. Notably, women have consistently been shown to have higher rates of 
periprocedural complications including major vascular complications, stroke, and major lifethreatening bleeding [116, 118, 119]. Additionally, women tend to have lower coronary heights and smaller annuli, which increases their risk of coronary obstruction, patient prosthesis mismatch, as well annular rupture [119-121]. Women represent a larger portion of patients requiring alternative access TAVR likely due to smaller diameter femoral arteries in women [119]. Given these unique anatomic and procedural outcomes, women with severe AS who are at low surgical risk should be given special consideration for SAVR given the consistently worse periprocedural complications seen in this group.

\section{NEED FOR CONCOMITANT PROCEDURE}

CAD is common in patients with severe AS, and among patients in the Evolut Low Risk and PARTNER 3 low-risk trials, the baseline history of prior PCI was 13 and $28 \%$, respectively $[7,8,107,122]$. In both trials, approximately $7 \%$ of patients in the TAVR group underwent concomitant PCI while $13 \%$ of patients in the SAVR group underwent coronary artery bypass grafting surgery (CABG). In both trials, patients with significant left main disease and those with complex CAD defined as a SYNTAX score $>22$ in Evolut Low Risk and > 32 in PARTNER 3 were excluded. It is curious why the rate of revascularization was nearly double in the surgical arm of both trials and what impact that may have on future cardiovascular events. In the PARTNER 2 trial, CABG or PCI at the time of aortic valve intervention did not impact short-term outcomes [3]. Others have shown that patients with comorbid CAD have significantly worse 30-day and 1-year outcomes after TAVR compared to those without CAD [123-125]. Complete surgical revascularization has been consistently shown to improve outcomes in patients with multivessel CAD, and in those patients undergoing SAVR, guidelines recommend concomitant CABG [9]. There is no consensus on what types of lesions should be revascularized prior to TAVR as benefit has not been consistently shown and prospective trials are ongoing [126]. At this time, low-risk severe AS patients with significant, multivessel coronary artery disease or left main disease should be guided towards SAVR with CABG.

Other co-existent valvular heart disease would also tilt a low-risk AS patient towards SAVR. Current guidelines recommend patients with asymptomatic moderate and severe primary mitral regurgitation to undergo mitral valve repair or replacement at the time of cardiac surgery for other indications [80]. Additionally, as discussed previously, the presence of a dilated ascending aorta, especially in low surgical risk patients with bicuspid AS, should be guided towards SAVR with aortic root repair [127]. It is still unclear how to manage patients with borderline or mildly dilated aortas where interval imaging is not available to assess for rate of aneurysm expansion. Patients with chronic atrial fibrillation may benefit from a MAZE with left atrial appendage excision. Ongoing studies including the WATCH-TAVR trial evaluating the safety and efficacy of concomitant TAVR and left atrial appendage occlusion in severe AS patients with atrial fibrillation (NCT03173534), are needed to better inform treatment strategies in low-risk patients.

\section{CONCLUSIONS}

The publication of the low-risk TAVR trials represents a tremendous advance in the management of aortic stenosis and speaks to the significant progress made in the development of THV technology, cardiovascular imaging, and operator technique. It is likely that the volume of low-risk patients being evaluated by heart teams will increase exponentially, and many informed patients with aortic valve disease will come seeking percutaneous options. However, as outlined in this review, the low-risk trials were performed in carefully selected low-risk patients and the results are not generalizable to all low-risk AS patients. Significant unknowns remain regarding the outcomes of TAVR in patients with bicuspid AS, patients adverse asymmetric annular calcification, and those with significant co-morbid multivessel CAD. In 


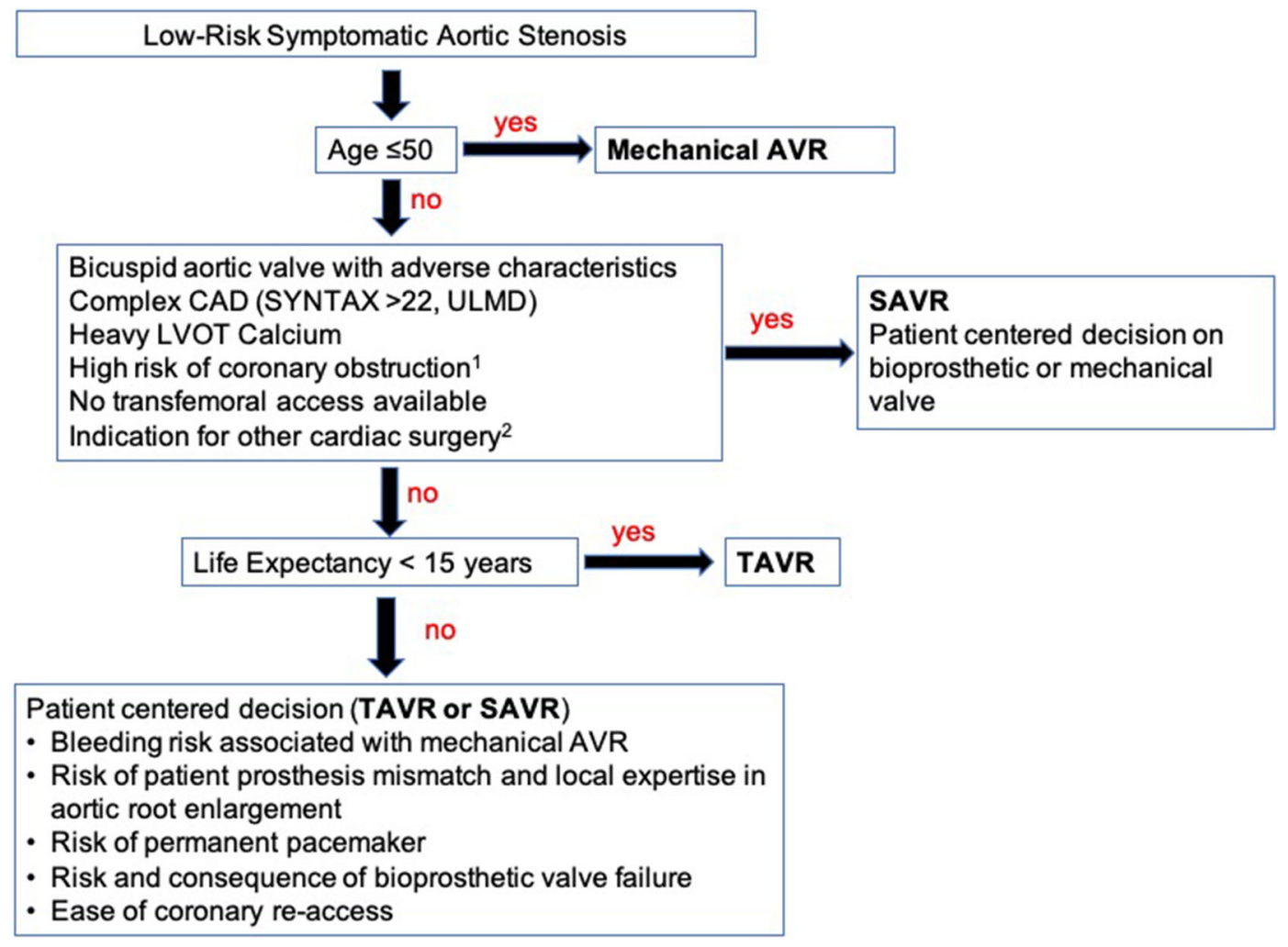

Fig. 4 Proposed assessment of severe symptomatic aortic stenosis patient at low surgical risk. ${ }^{1}$ Coronary height $\leq 11 \mathrm{~mm} .{ }^{2}$ Multivessel coronary artery disease, severe mitral regurgitation/stenosis, ascending aortic aneurysm $>5.0 \mathrm{~cm}$. Aortic valve replacement (AVR); coronary artery disease (CAD); synergy between

addition, as we shift to implanting these devices in younger patients, the long-term durability of THV will need to be carefully studied as will outcomes for patients being treated for failed THVs. In sum, despite the incredible results of the low-risk TAVR trials, SAVR will continue to have a central role in the management of many low-surgical risk AS patients (Fig. 4).

\section{ACKNOWLEDGEMENTS}

Funding. No funding or sponsorship was received for this study or publication of this article. percutaneous coronary intervention with Taxus and cardiac surgery (SYNTAX); unprotected left main disease (UPLM); left ventricular outflow tract obstruction (LVOT); surgical aortic valve replacement (SAVR); transcatheter aortic valve replacement (TAVR)

Authorship. All named authors meet the International Committee of Medical Journal Editors (ICMJE) criteria for authorship for this article, take responsibility for the integrity of the work as a whole, and have given their approval for this version to be published.

Disclosures. Kunal V. Patel, Wally Omar, Pedro Engel Gonzalez, Michael E. Jessen, Lynn Huffman, and Dharam J. Kumbhani have nothing to disclose. Anthony A. Bavry is a member of the journal's editorial board.

Compliance with Ethics Guidelines. This article is based on previously conducted studies and does not contain any studies with human participants or animals performed by any of the authors. 
Data Availability. Data sharing is not applicable to this article as no datasets were generated or analyzed during the current study.

Open Access. This article is licensed under a Creative Commons Attribution-NonCommercial 4.0 International License, which permits any non-commercial use, sharing, adaptation, distribution and reproduction in any medium or format, as long as you give appropriate credit to the original author(s) and the source, provide a link to the Creative Commons licence, and indicate if changes were made. The images or other third party material in this article are included in the article's Creative Commons licence, unless indicated otherwise in a credit line to the material. If material is not included in the article's Creative Commons licence and your intended use is not permitted by statutory regulation or exceeds the permitted use, you will need to obtain permission directly from the copyright holder. To view a copy of this licence, visit http://creativecommons.org/licenses/by$\mathrm{nc} / 4.0 /$.

\section{REFERENCES}

1. Adams DH, Popma JJ, Reardon MJ, Yakubov SJ, Coselli JS, Deeb GM, et al. Transcatheter aorticvalve replacement with a self-expanding prosthesis. N Engl J Med. 2014;370(19):1790-8.

2. Smith CR, Leon MB, Mack MJ, Miller DC, Moses JW, Svensson LG, et al. Transcatheter versus surgical aortic-valve replacement in high-risk patients. N Engl J Med. 2011;364(23):2187-98.

3. Leon MB, Smith CR, Mack MJ, Makkar RR, Svensson LG, Kodali SK, et al. Transcatheter or surgical aorticvalve replacement in intermediate-risk patients. N Engl J Med. 2016;374(17):1609-20.

4. Reardon MJ, Van Mieghem NM, Popma JJ, Kleiman NS, Sondergaard L, Mumtaz M, et al. Surgical or transcatheter aortic-valve replacement in intermediate-risk patients. N Engl J Med. 2017;376(14): 1321-31.

5. Thourani VH, Suri RM, Gunter RL, Sheng S, O'Brien SM, Ailawadi G, et al. Contemporary real-world outcomes of surgical aortic valve replacement in 141,905 low-risk, intermediate-risk, and high-risk patients. Ann Thorac Surg. 2015;99(1):55-61.
6. Otto CM, Kumbhani DJ, Alexander KP, Calhoon JH, Desai MY, Kaul S, et al. 2017 ACC expert consensus decision pathway for transcatheter aortic valve replacement in the management of adults with aortic stenosis: a report of the American College of Cardiology Task Force on Clinical Expert Consensus Documents. J Am Coll Cardiol. 2017;69(10): 1313-46.

7. Mack MJ, Leon MB, Thourani VH, Makkar R, Kodali SK, Russo $M$, et al. Transcatheter aortic-valve replacement with a balloon-expandable valve in low-risk patients. N Engl J Med. 2019;380(18): 1695-705.

8. Popma JJ, Deeb GM, Yakubov SJ, Mumtaz M, Gada $\mathrm{H}$, O'Hair D, et al. Transcatheter aortic-valve replacement with a self-expanding valve in low-risk patients. N Engl J Med. 2019;380(18):1706-15.

9. Nishimura RA, Otto CM, Bonow RO, Carabello BA, Erwin JP 3rd, Guyton RA, et al. 2014 AHA/ACC guideline for the management of patients with valvular heart disease: executive summary: a report of the American College of Cardiology/American Heart Association Task Force on Practice Guidelines. J Am Coll Cardiol. 2014;63(22):2438-88.

10. Roberts WC, Ko JM. Frequency by decades of unicuspid, bicuspid, and tricuspid aortic valves in adults having isolated aortic valve replacement for aortic stenosis, with or without associated aortic regurgitation. Circulation. 2005;111(7):920-5.

11. Kong WKF, Delgado V, Bax JJ. Bicuspid aortic valve: what to image in patients considered for transcatheter aortic valve replacement? Circ Cardiovasc Imaging. 2017;10(9):e005987.

12. Scharfschwerdt M, Meyer-Saraei R, Schmidtke C, Sievers HH. Hemodynamics of the Edwards Sapien XT transcatheter heart valve in noncircular aortic annuli. J Thorac Cardiovasc Surg. 2014;148(1): 126-32.

13. Sievers HH, Schmidtke C. A classification system for the bicuspid aortic valve from 304 surgical specimens. J Thorac Cardiovasc Surg. 2007;133(5): 1226-33.

14. Tchetche D, de Biase C, van Gils L, Parma R, Ochala $\mathrm{A}$, Lefevre $\mathrm{T}$, et al. Bicuspid aortic valve anatomy and relationship with devices: the BAVARD Multicenter Registry. Circ Cardiovasc Interv. 2019;12(1): e007107.

15. Kanjanahattakij N, Horn B, Vutthikraivit W, Biso SM, Ziccardi MR, Lu MLR, et al. Comparing outcomes after transcatheter aortic valve replacement in patients with stenotic bicuspid and tricuspid aortic valve: a systematic review and meta-analysis. Clin Cardiol. 2018;41(7):896-902. 
16. Yoon SH, Bleiziffer S, De Backer O, Delgado V, Arai $\mathrm{T}$, Ziegelmueller J, et al. Outcomes in transcatheter aortic valve replacement for bicuspid versus tricuspid aortic valve stenosis. J Am Coll Cardiol. 2017;69(21):2579-89.

17. Halim SA, Edwards FH, Dai D, Li Z, Mack MJ, Holmes DR, et al. Outcomes of transcatheter aortic valve replacement in patients with bicuspid aortic valve disease: a report from the Society of Thoracic Surgeons/American College of Cardiology Transcatheter Valve Therapy Registry. Circulation. 2020;141(13):1071-9.

18. Makkar RR, Yoon SH, Leon MB, Chakravarty T, Rinaldi M, Shah PB, et al. Association between transcatheter aortic valve replacement for bicuspid vs tricuspid aortic stenosis and mortality or stroke. JAMA. 2019;321(22):2193-202.

19. Yoon SH, Lefevre T, Ahn JM, Perlman GY, Dvir D, Latib A, et al. Transcatheter aortic valve replacement with early- and new-generation devices in bicuspid aortic valve stenosis. J Am Coll Cardiol. 2016;68(11):1195-205.

20. Elbadawi A, Saad M, Elgendy IY, Barssoum K, Omer MA, Soliman A, et al. Temporal trends and outcomes of transcatheter versus surgical aortic valve replacement for bicuspid aortic valve stenosis. JACC Cardiovasc Interv. 2019;12(18):1811-22.

21. Waksman R, Craig PE, Torguson R, Asch FM, Weissman G, Ruiz D, et al. Transcatheter aortic valve replacement in low-risk patients with symptomatic severe bicuspid aortic valve stenosis. JACC Cardiovasc Interv. 2020;13(9):1019-27.

22. Accf/Aha/Aats/Acr/Asa/Sca/Scai/Sir/Sts/Svm Guidelines For The D, Management of Patients With Thoracic Aortic Disease Representative M, Hiratzka LF, Creager MA, Isselbacher EM, Svensson LG, et al. Surgery for aortic dilatation in patients with bicuspid aortic valves: a statement of clarification from the American College of Cardiology/American Heart Association Task Force on Clinical Practice Guidelines. Circulation. 2016;133(7):680-6.

23. Svensson LG, Kim KH, Blackstone EH, Rajeswaran J, Gillinov AM, Mihaljevic T, et al. Bicuspid aortic valve surgery with proactive ascending aorta repair. J Thorac Cardiovasc Surg. 2011;142(3):622-9, 9e1-3.

24. Colombo A, Mangieri A. Surgery versus TAVR for bicuspid aortic valve disease: the time has come for a randomized study. JACC Cardiovasc Interv. 2020;13(9):1028-9.

25. Kodali SK, Velagapudi P, Hahn RT, Abbott D, Leon MB. Valvular heart disease in patients $\geq 80$ years of age. J Am Coll Cardiol. 2018;71(18):2058-72.
26. Yoon SH, Schmidt T, Bleiziffer S, Schofer N, Fiorina C, Munoz-Garcia AJ, et al. Transcatheter aortic valve replacement in pure native aortic valve regurgitation. J Am Coll Cardiol. 2017;70(22):2752-63.

27. Bahlmann E, Cramariuc D, Minners J, Lonnebakken MT, Ray S, Gohlke-Baerwolf C, et al. Small aortic root in aortic valve stenosis: clinical characteristics and prognostic implications. Eur Heart J Cardiovasc Imaging. 2017;18(4):404-12.

28. Coutinho GF, Correia PM, Pauperio G, de Oliveira F, Antunes MJ. Aortic root enlargement does not increase the surgical risk and short-term patient outcome? Eur J Cardiothorac Surg. 2011;40(2): $441-7$.

29. Kulik A, Al-Saigh M, Chan V, Masters RG, Bedard P, Lam BK, et al. Enlargement of the small aortic root during aortic valve replacement: is there a benefit? Ann Thorac Surg. 2008;85(1):94-100.

30. Mauri V, Kim WK, Abumayyaleh M, Walther T, Moellmann H, Schaefer U, et al. Short-term outcome and hemodynamic performance of next-generation self-expanding versus balloon-expandable transcatheter aortic valves in patients with small aortic annulus: a multicenter propensity-matched comparison. Circ Cardiovasc Interv. 2017;10(10): e005013.

31. Freitas-Ferraz AB, Tirado-Conte G, Dagenais F, Ruel M, Al-Atassi T, Dumont E, et al. Aortic stenosis and small aortic annulus. Circulation. 2019;139(23): 2685-702.

32. Wagner IM, Eichinger WB, Bleiziffer S, Botzenhardt $\mathrm{F}$, Gebauer I, Guenzinger R, et al. Influence of completely supra-annular placement of bioprostheses on exercise hemodynamics in patients with a small aortic annulus. J Thorac Cardiovasc Surg. 2007;133(5):1234-41.

33. Pibarot P, Dumesnil JG. Hemodynamic and clinical impact of prosthesis-patient mismatch in the aortic valve position and its prevention. J Am Coll Cardiol. 2000;36(4):1131-41.

34. Pibarot P, Dumesnil JG. Prosthesis-patient mismatch: definition, clinical impact, and prevention. Heart. 2006;92(8):1022-9.

35. Dayan V, Vignolo G, Soca G, Paganini JJ, Brusich D, Pibarot P. Predictors and outcomes of prosthesis-patient mismatch after aortic valve replacement. JACC Cardiovasc Imaging. 2016;9(8):924-33.

36. Fallon JM, DeSimone JP, Brennan JM, O'Brien S, Thibault DP, DiScipio AW, et al. The incidence and consequence of prosthesis-patient mismatch after surgical aortic valve replacement. Ann Thorac Surg. 2018;106(1):14-22. 
37. Clavel MA, Webb JG, Pibarot P, Altwegg L, Dumont E, Thompson C, et al. Comparison of the hemodynamic performance of percutaneous and surgical bioprostheses for the treatment of severe aortic stenosis. J Am Coll Cardiol. 2009;53(20):1883-91.

38. Puri R, Byrne J, Muller R, Baumbach H, Eltchaninoff $\mathrm{H}$, Redwood $\mathrm{S}$, et al. Transcatheter aortic valve implantation in patients with small aortic annuli using a $20 \mathrm{~mm}$ balloon-expanding valve. Heart. 2017;103(2):148-53.

39. Rodes-Cabau J, Pibarot P, Suri RM, Kodali S, Thourani VH, Szeto WY, et al. Impact of aortic annulus size on valve hemodynamics and clinical outcomes after transcatheter and surgical aortic valve replacement: insights from the PARTNER Trial. Circ Cardiovasc Interv. 2014;7(5):701-11.

40. Pasic M, Unbehaun A, Buz S, Drews T, Hetzer R. Annular rupture during transcatheter aortic valve replacement: classification, pathophysiology, diagnostics, treatment approaches, and prevention. JACC Cardiovasc Interv. 2015;8(1 Pt A):1-9.

41. Ribeiro HB, Nombela-Franco L, Urena M, Mok M, Pasian S, Doyle D, et al. Coronary obstruction following transcatheter aortic valve implantation: a systematic review. JACC Cardiovasc Interv. 2013;6(5):452-61.

42. Castro LJ, Arcidi JM Jr, Fisher AL, Gaudiani VA. Routine enlargement of the small aortic root: a preventive strategy to minimize mismatch. Ann Thorac Surg. 2002;74(1):31-6 (Discussion 6).

43. John D, Buellesfeld L, Yuecel S, Mueller R, Latsios G, Beucher $\mathrm{H}$, et al. Correlation of Device landing zone calcification and acute procedural success in patients undergoing transcatheter aortic valve implantations with the self-expanding CoreValve prosthesis. JACC Cardiovasc Interv. 2010;3(2): 233-43.

44. Langer NB, Hamid NB, Nazif TM, Khalique OK, Vahl $\mathrm{TP}$, White $\mathrm{J}$, et al. Injuries to the aorta, aortic annulus, and left ventricle during transcatheter aortic valve replacement: management and outcomes. Circ Cardiovasc Interv. 2017;10(1):e004735.

45. Barbanti M, Yang TH, Rodes Cabau J, Tamburino C, Wood DA, Jilaihawi $\mathrm{H}$, et al. Anatomical and procedural features associated with aortic root rupture during balloon-expandable transcatheter aortic valve replacement. Circulation. 2013;128(3): 244-53.

46. Ewe SH, Ng AC, Schuijf JD, van der Kley F, Colli A, Palmen $\mathrm{M}$, et al. Location and severity of aortic valve calcium and implications for aortic regurgitation after transcatheter aortic valve implantation. Am J Cardiol. 2011;108(10):1470-7.
47. Koos R, Mahnken AH, Dohmen G, Brehmer K, Gunther RW, Autschbach R, et al. Association of aortic valve calcification severity with the degree of aortic regurgitation after transcatheter aortic valve implantation. Int J Cardiol. 2011;150(2):142-5.

48. Pollari F, Dell'Aquila AM, Sohn C, Marianowicz J, Wiehofsky P, Schwab J, et al. Risk factors for paravalvular leak after transcatheter aortic valve replacement. J Thorac Cardiovasc Surg. 2019;157(4):1406-15 (e3).

49. Pibarot P, Hahn RT, Weissman NJ, Arsenault M, Beaudoin J, Bernier M, et al. Association of paravalvular regurgitation with 1-year outcomes after transcatheter aortic valve replacement with the SAPIEN 3 valve. JAMA Cardiol. 2017;2(11):1208-16.

50. Thyregod HGH, Ihlemann N, Jorgensen TH, Nissen $\mathrm{H}$, Kjeldsen BJ, Petursson P, et al. Five-year clinical and echocardiographic outcomes from the Nordic Aortic Valve Intervention (NOTION) randomized clinical trial in lower surgical risk patients. Circulation. 2019;139:2714-23.

51. Kodali SK, Williams MR, Smith CR, Svensson LG, Webb JG, Makkar RR, et al. Two-year outcomes after transcatheter or surgical aortic-valve replacement. N Engl J Med. 2012;366(18):1686-95.

52. Kapadia SR, Kodali S, Makkar R, Mehran R, Lazar RM, Zivadinov R, et al. Protection against cerebral embolism during transcatheter aortic valve replacement. J Am Coll Cardiol. 2017;69(4):367-77.

53. Seeger J, Gonska B, Otto M, Rottbauer W, Wohrle J. Cerebral embolic protection during transcatheter aortic valve replacement significantly reduces death and stroke compared with unprotected procedures. JACC Cardiovasc Interv. 2017;10(22):2297-303.

54. Nombela-Franco L, Rodes-Cabau J, DeLarochelliere R, Larose E, Doyle D, Villeneuve J, et al. Predictive factors, efficacy, and safety of balloon post-dilation after transcatheter aortic valve implantation with a balloon-expandable valve. JACC Cardiovasc Interv. 2012;5(5):499-512.

55. Nombela-Franco L, Webb JG, de Jaegere PP, Toggweiler S, Nuis RJ, Dager AE, et al. Timing, predictive factors, and prognostic value of cerebrovascular events in a large cohort of patients undergoing transcatheter aortic valve implantation. Circulation. 2012;126(25):3041-53.

56. Beurtheret S, Karam N, Resseguier N, Houel R, Modine T, Folliguet T, et al. Femoral versus nonfemoral peripheral access for transcatheter aortic valve replacement. J Am Coll Cardiol. 2019;74(22): 2728-39. 
57. Allen KB, Chhatriwalla AK, Cohen D, Saxon J, Hawa Z, Kennedy KF, et al. Transcarotid versus transapical and transaortic access for transcatheter aortic valve replacement. Ann Thorac Surg. 2019;108(3): 715-22.

58. Blackstone EH, Suri RM, Rajeswaran J, Babaliaros V, Douglas PS, Fearon WF, et al. Propensity-matched comparisons of clinical outcomes after transapical or transfemoral transcatheter aortic valve replacement: a placement of aortic transcatheter valves (PARTNER)-I trial substudy. Circulation. 2015;131(22):1989-2000.

59. Chandrasekhar J, Hibbert B, Ruel M, Lam BK, Labinaz M, Glover C. Transfemoral vs non-transfemoral access for transcatheter aortic valve implantation: a systematic review and meta-analysis. Can J Cardiol. 2015;31(12):1427-38.

60. Dahle TG, Kaneko T, McCabe JM. Outcomes following subclavian and axillary artery access for transcatheter aortic valve replacement: society of the thoracic surgeons/American College of Cardiology TVT Registry Report. JACC Cardiovasc Interv. 2019;12(7):662-9.

61. Elmariah S, Fearon WF, Inglessis I, Vlahakes GJ, Lindman BR, Alu MC, et al. Transapical transcatheter aortic valve replacement is associated with increased cardiac mortality in patients with left ventricular dysfunction: insights from the PARTNER I trial. JACC Cardiovasc Interv. 2017;10(23): 2414-22.

62. Greenbaum AB, Babaliaros VC, Chen MY, Stine AM, Rogers T, O'Neill WW, et al. Transcaval access and closure for transcatheter aortic valve replacement: a prospective investigation. J Am Coll Cardiol. 2017;69(5):511-21.

63. O'Hair DP, Bajwa TK, Popma JJ, Watson DR, Yakubov SJ, Adams DH, et al. Direct aortic access for transcatheter aortic valve replacement using a selfexpanding device. Ann Thorac Surg. 2018;105(2): 484-90.

64. Di Mario C, Goodwin M, Ristalli F, Ravani M, Meucci F, Stolcova M, et al. A prospective registry of intravascular lithotripsy-enabled vascular access for transfemoral transcatheter aortic valve replacement. JACC Cardiovasc Interv. 2019;12(5):502-4.

65. Palmerini T, Chakravarty T, Saia F, Bruno AG, Bacchi-Reggiani ML, Marrozzini C, et al. Coronary protection to prevent coronary obstruction during TAVR: a multicenter international registry. JACC Cardiovasc Interv. 2020;13(6):739-47.

66. Khan JM, Greenbaum AB, Babaliaros VC, Rogers T, Eng $\mathrm{MH}$, Paone $\mathrm{G}$, et al. The BASILICA trial: prospective multicenter investigation of intentional leaflet laceration to prevent TAVR coronary obstruction. JACC Cardiovasc Interv. 2019;12(13): 1240-52.

67. Rodes-Cabau J, Ellenbogen KA, Krahn AD, Latib A, Mack M, Mittal S, et al. Management of conduction disturbances associated with transcatheter aortic valve replacement: JACC scientific expert panel. J Am Coll Cardiol. 2019;74(8):1086-106.

68. Thiele H, Kurz T, Feistritzer HJ, Stachel G, Hartung $\mathrm{P}$, Eitel I, et al. Comparison of newer generation self-expandable vs. balloon-expandable valves in transcatheter aortic valve implantation: the randomized SOLVE-TAVI trial. Eur Heart J. 2020;41(20):1890-9.

69. Nazif TM, Chen S, George I, Dizon JM, Hahn RT, Crowley A, et al. New-onset left bundle branch block after transcatheter aortic valve replacement is associated with adverse long-term clinical outcomes in intermediate-risk patients: an analysis from the PARTNER II trial. Eur Heart J. 2019;40(27):2218-27.

70. Mouillet G, Lellouche N, Yamamoto M, Oguri A, Dubois-Rande JL, Van Belle E, et al. Outcomes following pacemaker implantation after transcatheter aortic valve implantation with CoreValve ${ }^{\circledR}$ devices: results from the FRANCE 2 Registry. Catheter Cardiovasc Interv. 2015;86(3):E158-66.

71. Mauri V, Reimann A, Stern D, Scherner M, Kuhn E, Rudolph V, et al. Predictors of permanent pacemaker implantation after transcatheter aortic valve replacement with the SAPIEN 3. JACC Cardiovasc Interv. 2016;9(21):2200-9.

72. Maeno Y, Abramowitz Y, Kawamori H, Kazuno Y, Kubo S, Takahashi N, et al. A Highly predictive risk model for pacemaker implantation after TAVR. JACC Cardiovasc Imaging. 2017;10(10 Pt A): 1139-47.

73. Gonska B, Seeger J, Kessler M, von Keil A, Rottbauer W, Wohrle J. Predictors for permanent pacemaker implantation in patients undergoing transfemoral aortic valve implantation with the Edwards Sapien 3 valve. Clin Res Cardiol. 2017;106(8):590-7.

74. Nazif TM, Dizon JM, Hahn RT, Xu K, Babaliaros V, Douglas PS, et al. Predictors and clinical outcomes of permanent pacemaker implantation after transcatheter aortic valve replacement: the PARTNER (Placement of AoRtic TraNscathetER Valves) trial and registry. JACC Cardiovasc Interv. 2015;8(1 Pt A):60-9.

75. Fadahunsi OO, Olowoyeye A, Ukaigwe A, Li Z, Vora $\mathrm{AN}$, Vemulapalli $S$, et al. Incidence, predictors, and outcomes of permanent pacemaker implantation following transcatheter aortic valve replacement: analysis from the U.S. Society of Thoracic Surgeons/ 
American College of Cardiology TVT Registry. JACC Cardiovasc Interv. 2016;9(21):2189-99.

76. Aljabbary T, Qiu F, Masih S, Fang J, Elbaz-Greener G, Austin PC, et al. Association of clinical and economic outcomes with permanent pacemaker implantation after transcatheter aortic valve replacement. JAMA Netw Open. 2018;1(1):e180088.

77. Cerrato E, Nombela-Franco L, Nazif TM, Eltchaninoff $\mathrm{H}$, Sondergaard L, Ribeiro HB, et al. Evaluation of current practices in transcatheter aortic valve implantation: the WRITTEN (WoRldwIde TAVI ExperieNce) survey. Int J Cardiol. 2017;228:640-7.

78. Regueiro A, Abdul-Jawad Altisent O, Del Trigo M, Campelo-Parada F, Puri R, Urena M, et al. Impact of new-onset left bundle branch block and periprocedural permanent pacemaker implantation on clinical outcomes in patients undergoing transcatheter aortic valve replacement: a systematic review and meta-analysis. Circ Cardiovasc Interv. 2016;9(5): e003635.

79. Forrest JK, Kaple RK, Tang GHL, Yakubov SJ, Nazif TM, Williams MR, et al. Three generations of selfexpanding transcatheter aortic valves: a report from the STS/ACC TVT registry. JACC Cardiovasc Interv. 2020;13(2):170-9.

80. Nishimura RA, O'Gara PT, Bonow RO. Guidelines update on indications for transcatheter aortic valve replacement. JAMA Cardiol. 2017;2(9):1036-7.

81. Goldstone AB, Chiu P, Baiocchi M, Lingala B, Patrick WL, Fischbein MP, et al. Mechanical or biologic prostheses for aortic-valve and mitral-valve replacement. N Engl J Med. 2017;377(19):1847-57.

82. Otto CM. Informed shared decisions for patients with aortic stenosis. N Engl J Med. 2019;380(18): 1769-70.

83. Rahimtoola SH. Choice of prosthetic heart valve in adults an update. J Am Coll Cardiol. 2010;55(22): 2413-26.

84. Chan V, Malas T, Lapierre H, Boodhwani M, Lam $\mathrm{BK}$, Rubens FD, et al. Reoperation of left heart valve bioprostheses according to age at implantation. Circulation. 2011;124(11 Suppl):S75-80.

85. Dvir D, Webb JG, Bleiziffer S, Pasic M, Waksman R, Kodali $\mathrm{S}$, et al. Transcatheter aortic valve implantation in failed bioprosthetic surgical valves. JAMA. 2014;312(2):162-70.

86. Barbanti M, Costa G, Zappulla P, Todaro D, Picci A, Rapisarda $G$, et al. Incidence of long-term structural valve dysfunction and bioprosthetic valve failure after transcatheter aortic valve replacement. J Am Heart Assoc. 2018;7(15):e008440.
87. Sondergaard L, Ihlemann N, Capodanno D, Jorgensen TH, Nissen H, Kjeldsen BJ, et al. Durability of transcatheter and surgical bioprosthetic aortic valves in patients at lower surgical risk. J Am Coll Cardiol. 2019;73(5):546-53.

88. Kumbhani DJ, Chhatriwalla AK. VIVID insights: tips for successful valve-in-valve TAVR in stented and stentless surgical valves. JACC Cardiovasc Interv. 2019;12(13):1264-7.

89. Dvir D, Bourguignon T, Otto CM, Hahn RT, Rosenhek R, Webb JG, et al. Standardized definition of structural valve degeneration for surgical and transcatheter bioprosthetic aortic valves. Circulation. 2018;137(4):388-99.

90. Capodanno D, Petronio AS, Prendergast B, Eltchaninoff H, Vahanian A, Modine T, et al. Standardized definitions of structural deterioration and valve failure in assessing long-term durability of transcatheter and surgical aortic bioprosthetic valves: a consensus statement from the European Association of Percutaneous Cardiovascular Interventions (EAPCI) endorsed by the European Society of Cardiology (ESC) and the European Association for Cardio-Thoracic Surgery (EACTS). Eur Heart J. 2017;38(45):3382-90.

91. Kappetein AP, Head SJ, Genereux P, Piazza N, van Mieghem NM, Blackstone EH, et al. Updated standardized endpoint definitions for transcatheter aortic valve implantation: the Valve Academic Research Consortium-2 consensus document. Eur Heart J. 2012;33(19):2403-18.

92. Testa L, Latib A, Brambilla N, De Marco F, Fiorina C, Adamo $\mathrm{M}$, et al. Long-term clinical outcome and performance of transcatheter aortic valve replacement with a self-expandable bioprosthesis. Eur Heart J. 2020;41:1876-86.

93. Kataruka A, Otto CM. Valve durability after transcatheter aortic valve implantation. J Thorac Dis. 2018;10(Suppl 30):S3629-36.

94. Chakravarty T, Sondergaard L, Friedman J, De Backer O, Berman D, Kofoed KF, et al. Subclinical leaflet thrombosis in surgical and transcatheter bioprosthetic aortic valves: an observational study. Lancet. 2017;389(10087):2383-92.

95. Makkar RR, Fontana G, Jilaihawi H, Chakravarty T, Kofoed KF, De Backer O, et al. Possible subclinical leaflet thrombosis in bioprosthetic aortic valves. N Engl J Med. 2015;373(21):2015-24.

96. Waksman R, Rogers T, Torguson R, Gordon P, Ehsan A, Wilson SR, et al. Transcatheter aortic valve replacement in low-risk patients with symptomatic severe aortic stenosis. J Am Coll Cardiol. 2018;72(18):2095-105. 
97. Tuzcu EM, Kapadia SR, Vemulapalli S, Carroll JD, Holmes DR Jr, Mack MJ, et al. Transcatheter aortic valve replacement of failed surgically implanted bioprostheses: the STS/ACC registry. J Am Coll Cardiol. 2018;72(4):370-82.

98. Tam DY, Dharma C, Rocha RV, Ouzounian M, Wijeysundera HC, Austin PC, et al. Transcatheter $\mathrm{ViV}$ versus redo surgical AVR for the management of failed biological prosthesis: early and late outcomes in a propensity-matched cohort. JACC Cardiovasc Interv. 2020;13(6):765-74.

99. Dauerman HL, Deeb GM, O'Hair DP, Waksman R, Yakubov SJ, Kleiman NS, et al. Durability and clinical outcomes of transcatheter aortic valve replacement for failed surgical bioprostheses. Circ Cardiovasc Interv. 2019;12(10):e008155.

100. Deeb GM, Reardon MJ, Chetcuti S, Patel HJ, Grossman PM, Yakubov SJ, et al. 3-year outcomes in highrisk patients who underwent surgical or transcatheter aortic valve replacement. J Am Coll Cardiol. 2016;67(22):2565-74.

101. Webb JG, Mack MJ, White JM, Dvir D, Blanke P, Herrmann HC, et al. Transcatheter aortic valve implantation within degenerated aortic surgical bioprostheses: PARTNER 2 valve-in-valve registry. J Am Coll Cardiol. 2017;69(18):2253-62.

102. Webb JG, Murdoch DJ, Alu MC, Cheung A, Crowley A, Dvir D, et al. 3-Year outcomes after valve-in-valve transcatheter aortic valve replacement for degenerated bioprostheses: the PARTNER 2 registry. J Am Coll Cardiol. 2019;73(21):2647-55.

103. Aziz M, Simonato M, Webb JG, Abdel-Wahab M, McElhinney D, Duncan A, et al. Mortality prediction after transcatheter treatment of failed bioprosthetic aortic valves utilizing various international scoring systems: Insights from the Valve-in-Valve International Data (VIVID). Catheter Cardiovasc Interv. 2018;92(6):1163-70.

104. Ejiofor JI, Yammine M, Harloff MT, McGurk S, Muehlschlegel JD, Shekar PS, et al. Reoperative surgical aortic valve replacement versus transcatheter valve-in-valve replacement for degenerated bioprosthetic aortic valves. Ann Thorac Surg. 2016;102(5):1452-8.

105. Neupane S, Singh H, Lammer J, Othman H, Yamasaki H, Rosman HS, et al. Meta-analysis of transcatheter valve-in-valve implantation versus redo aortic valve surgery for bioprosthetic aortic valve dysfunction. Am J Cardiol. 2018;121(12):1593-600.

106. Landes U, Webb JG, De Backer O, Sondergaard L, Abdel-Wahab M, Crusius L, et al. Repeat transcatheter aortic valve replacement for transcatheter prosthesis dysfunction. J Am Coll Cardiol. 2020;75(16):1882-93.

107. Goel SS, Ige M, Tuzcu EM, Ellis SG, Stewart WJ, Svensson LG, et al. Severe aortic stenosis and coronary artery disease-implications for management in the transcatheter aortic valve replacement era: a comprehensive review. J Am Coll Cardiol. 2013;62(1):1-10.

108. Vilalta V, Asmarats L, Ferreira-Neto AN, Maes F, de Freitas Campos Guimaraes L, Couture $\mathrm{T}$, et al. Incidence, clinical characteristics, and impact of acute coronary syndrome following transcatheter aortic valve replacement. JACC Cardiovasc Interv. 2018;11(24):2523-33.

109. Tang GHL, Zaid S, Ahmad H, Undemir C, Lansman SL. Transcatheter valve neo-commissural overlap with coronary orifices after transcatheter aortic valve replacement. Circ Cardiovasc Interv. 2018;11(10):e007263.

110. Ochiai T, Yoon SH, Flint N, Sharma R, Chakravarty $\mathrm{T}$, Kaewkes D, et al. Timing and outcomes of percutaneous coronary intervention in patients who underwent transcatheter aortic valve implantation. Am J Cardiol. 2020;125(9):1361-8.

111. Arnold SV, Spertus JA, Vemulapalli S, Li Z, Matsouaka RA, Baron SJ, et al. Quality-of-life outcomes after transcatheter aortic valve replacement in an unselected population: a report from the STS/ACC transcatheter valve therapy registry. JAMA Cardiol. 2017;2(4):409-16.

112. Baron SJ, Arnold SV, Reynolds MR, Wang K, Deeb M, Reardon MJ, et al. Durability of quality of life benefits of transcatheter aortic valve replacement: Long-term results from the CoreValve US extreme risk trial. Am Heart J. 2017;194:39-48.

113. Reynolds MR, Magnuson EA, Wang K, Thourani VH, Williams M, Zajarias A, et al. Health-related quality of life after transcatheter or surgical aortic valve replacement in high-risk patients with severe aortic stenosis: results from the PARTNER (Placement of AoRTic TraNscathetER Valve) Trial (Cohort A). J Am Coll Cardiol. 2012;60(6):548-58.

114. Hayashida K, Morice MC, Chevalier B, Hovasse T, Romano M, Garot P, et al. Sex-related differences in clinical presentation and outcome of transcatheter aortic valve implantation for severe aortic stenosis. J Am Coll Cardiol. 2012;59(6):566-71.

115. Humphries KH, Toggweiler S, Rodes-Cabau J, Nombela-Franco L, Dumont E, Wood DA, et al. Sex differences in mortality after transcatheter aortic valve replacement for severe aortic stenosis. J Am Coll Cardiol. 2012;60(10):882-6. 
116. Zhao ZG, Liao YB, Peng Y, Chai H, Liu W, Li Q, et al. Sex-related differences in outcomes after transcatheter aortic valve implantation: a systematic review and meta-analysis. Circ Cardiovasc Interv. 2013;6(5):543-51.

117. Szerlip M, Gualano S, Holper E, Squiers JJ, White JM, Doshi D, et al. Sex-specific outcomes of transcatheter aortic valve replacement with the SAPIEN 3 valve: insights from the PARTNER II S3 high-risk and intermediate-risk cohorts. JACC Cardiovasc Interv. 2018;11(1):13-20.

118. Doshi R, Shlofmitz E, Meraj P. Comparison of outcomes and complications of transcatheter aortic valve implantation in women versus men (from the National Inpatient Sample). Am J Cardiol. 2018;121(1):73-7.

119. O'Connor SA, Morice MC, Gilard M, Leon MB, Webb JG, Dvir D, et al. Revisiting sex equality with transcatheter aortic valve replacement outcomes: a collaborative, patient-level meta-analysis of 11,310 patients. J Am Coll Cardiol. 2015;66(3):221-8.

120. Buellesfeld L, Stortecky S, Kalesan B, Gloekler S, Khattab AA, Nietlispach F, et al. Aortic root dimensions among patients with severe aortic stenosis undergoing transcatheter aortic valve replacement. JACC Cardiovasc Interv. 2013;6(1): 72-83.

121. Ribeiro HB, Webb JG, Makkar RR, Cohen MG, Kapadia SR, Kodali S, et al. Predictive factors, management, and clinical outcomes of coronary obstruction following transcatheter aortic valve implantation: insights from a large multicenter registry. J Am Coll Cardiol. 2013;62(17):1552-62.

122. Cao D, Chiarito M, Pagnotta P, Reimers B, Stefanini GG. Coronary revascularisation in transcatheter aortic valve implantation candidates: why, who, when? Interv Cardiol. 2018;13(2):69-76.
123. Witberg G, Regev E, Chen S, Assali A, Barbash IM, Planer D, et al. The prognostic effects of coronary disease severity and completeness of revascularization on mortality in patients undergoing transcatheter aortic valve replacement. JACC Cardiovasc Interv. 2017;10(14):1428-35.

124. Sankaramangalam K, Banerjee K, Kandregula K, Mohananey D, Parashar A, Jones BM, et al. Impact of coronary artery disease on 30-day and 1-year mortality in patients undergoing transcatheter aortic valve replacement: a meta-analysis. J Am Heart Assoc. 2017;6(10):e006092.

125. Dewey TM, Brown DL, Herbert MA, Culica D, Smith $\mathrm{CR}$, Leon $\mathrm{MB}$, et al. Effect of concomitant coronary artery disease on procedural and late outcomes of transcatheter aortic valve implantation. Ann Thorac Surg. 2010;89(3):758-67 (Discussion 67).

126. Faroux L, Guimaraes L, Wintzer-Wehekind J, Junquera L, Ferreira-Neto AN, Del Val D, et al. Coronary artery disease and transcatheter aortic valve replacement: JACC state-of-the-art review. J Am Coll Cardiol. 2019;74(3):362-72.

127. Hiratzka LF, Bakris GL, Beckman JA, Bersin RM, Carr VF, Casey DE Jr, et al. 2010 ACCF/AHA/AATS/ACR/ ASA/SCA/SCAI/SIR/STS/SVM guidelines for the diagnosis and management of patients with Thoracic Aortic Disease: a report of the American College of Cardiology Foundation/American Heart Association Task Force on Practice Guidelines, American Association for Thoracic Surgery, American College of Radiology, American Stroke Association, Society of Cardiovascular Anesthesiologists, Society for Cardiovascular Angiography and Interventions, Society of Interventional Radiology, Society of Thoracic Surgeons, and Society for Vascular Medicine. Circulation. 2010;121(13): e266-369. 